\title{
PI3Kdelta Inhibitor GS-9901
}

\author{
National Cancer Institute
}

\section{Source}

National Cancer Institute. PI3Kdelta Inhibitor GS-9901. NCI Thesaurus. Code C121374.

An orally bioavailable, small molecule inhibitor of the delta isoform of phosphoinositide-3 kinase (PI3Kdelta) with potential immunomodulating and antineoplastic activities. Upon oral administration, PI3Kdelta inhibitor GS-9901 selectively binds to the delta isoform of PI3K and inhibits its activity. This inhibits the activation of the PI3Kdelta-mediated signaling pathway and prevents proliferation of PI3Kdelta-overexpressing tumor cells. Unlike other isoforms of PI3K, PI3Kdelta is expressed primarily in certain tumor cell types and plays a key role in tumor cell proliferation, motility and survival. The targeted inhibition of PI3Kdelta is designed to preserve PI3K signaling in normal, non-neoplastic cells and thus reduces toxicity to normal, healthy cells. 